\title{
Physicians' attitudes to four common problems: hypertension, atrial fibrillation, transient ischaemic attacks, and angina pectoris
}

\author{
C A BUCKNALL, G K MORRIS, J R A MITCHELL
}

\begin{abstract}
A questionnaire was completed by 341 senior physicians on their attitudes to four common cardiovascular problems. Their replies showed that uncertainty about the end point for diastolic blood pressure still prevails and that their approach to the management of hypertension of differing severity in men and women of varying ages stems more from personal belief than from the results of clinical trials. Unless patients with atrial fibrillation also had mitral valve disease anticoagulation was not thought to be necessary, thereby making it ethically possible to carry out a trial of anticoagulants in stroke prevention on patients with atrial fibrillation but no valvular disease. The physicians' suggestions for very active management in transient ischaemic attacks extended beyond the evidence available to them, whereas their approach to the use of coronary arteriography closely reflected the results of clinical trials.

These findings may indicate that recent cardiovascular trials that have provided definitive results have had more impact than earlier inadequate studies.
\end{abstract}

King's College Hospital, London

C A BUCKNALL, MB, MRCP, registrar in cardiology

Department of Medicine, University Hospital, Queen's Medical Centre, Nottingham NG7 2UH

G K MORRIS, MD, FRCP, consultant physician, City and University Hospitals, Nottingham

J R A MITCHELL, MD, FRCP, foundation professor of medicine, Nottingham Medical School

Correspondence to: Professor Mitchell.

\section{Introduction}

Physicians are under increasing pressure from their profession and consumer groups to adopt a more aggressive stance in detecting and treating cardiovascular risk factors, such as systemic arterial hypertension. They are also being urged to be more active in managing conditions such as transient ischaemic cerebral attacks and angina pectoris which may herald a completed stroke or myocardial infarction. Before they can persuade their patients to accept drug treatment, invasive tests, surgical intervention, or changes in lifestyle they have to convince themselves that what they are advising is beneficial. There is, however, no general agreement on the best way to define mild to moderate hypertension or to treat atrial fibrillation, transient ischaemic attacks, and angina pectoris.

To determine the extent of this uncertainty and to compare the advice that physicians would have offered with the evidence available to them at the time we sent a questionnaire to senior clinicians who were likely to be handling such problems in their daily work.

\section{Methods}

A questionnaire, a prepaid envelope, and a covering letter explaining the purpose of the survey were sent to 641 physicians; 343 were members of the Association of Physicians of Great Britain and Ireland, 254 were members of the British Cardiac Society, and 44 were members of both. They were asked to indicate whether they regarded themselves as general physicians, cardiologists, or physicians with an interest in cardiology. The questionnaire had four major sections, and the following answers were requested.

Blood pressure-Firstly, they were asked whether they used phase IV or V when measuring diastolic blood pressure. Secondly, they were asked to asssume that "the blood pressures shown represent repeatable pressures for patients who have no symptoms and no correctable causes for raised blood pressure." They were then asked to indicate with a tick in the appropriate box the lowest level of pressure that they would treat in men belonging to the 
age groups given. There were three age groups $(30-49,50-69$, and $\geq 70)$; for each age group they could select systolic pressures of 140-150, 151-160, $161-170,171-180$, and $>180$ and diastolic pressures of $\leqslant 90,91-95,96-100$, $101-105,106-110$, and $>110$. They were then asked whether they applied the same criteria to women and if not they were requested to complete a similar table for women.

TABLE I-Measuring diastolic blood pressure: percentage of respondents using stated end points

\begin{tabular}{lcccc}
\hline End points & $\begin{array}{c}\text { All respondents } \\
(\mathrm{n}=341)\end{array}$ & $\begin{array}{c}\text { Physicians } \\
(\mathrm{n}=189)\end{array}$ & $\begin{array}{c}\text { Cardiologists } \\
(\mathrm{n}=102)\end{array}$ & $\begin{array}{c}\text { Physicians with } \\
\text { interest } \\
(\mathrm{n}=50)\end{array}$ \\
\hline Phase IV & $50 \cdot 8$ & $59 \cdot 6$ & $46 \cdot 5$ & $26 \cdot 5$ \\
Phase V & $43 \cdot 8$ & $37 \cdot 1$ & $46 \cdot 5$ & $63 \cdot 3$ \\
Both & $5 \cdot 4$ & $3 \cdot 3$ & $7 \cdot 0$ & $10 \cdot 2$ \\
\hline
\end{tabular}

Atrial fibrillation-They were asked to assume that cardioversion had been unsuccessful or was not to be attempted and that anticoagulation was not contraindicated. They were then asked: "To reduce the risk of systemic embolism do you routinely anticoagulate patients in atrial fibrillation in

\section{Blood pressure}

Diastolic end point-Table I shows that there was a gradation from the general physicians, of whom almost two thirds used muffling of the Korotkoff sounds as their end point, through cardiologists, who were evenly divided between muffling and disappearance as the end point, to physicians "with an interest," of whom two thirds used phase V.

Sex differences in treatment thresholds-Although $70 \%$ of physicians (231 out of 330 with analysable responses) would have treated men and women on similar criteria, there was again a graded response from general physicians, of whom $64(35 \%)$ would have used different thresholds, through cardiologists, of whom $28(28 \%)$ would have used different thresholds, to the physicians with an interest, of whom only one seventh (7) would have used different thresholds for the sexes.

Lowest levels of pressure at which treatment was recommended-Table II shows the levels recommended by those physicians who did not use different criteria for men and women; a significant number of them would not have treated systolic hypertension, irrespective of the patient's age, and this proportion increased substantially to $61(25 \cdot 3 \%)$ when the over 70 s were under consideration. For those physicians who would have offered treatment the modal level at which they would have recommended treatment was 151-160 for the 30-49 age group, 161-170 for the 50-59 group, and >180 for the over 70s. Very few physicians would not have offered treatment on the basis of the diastolic readings, and the modal level for recommending treatment moved up again with age (91-95 in the 30-49 year group, 101-105 for the 50-69 group, and $>110$ in the over $70 \mathrm{~s}$ ).

\begin{tabular}{|c|c|c|c|c|c|c|c|c|c|c|c|c|c|c|}
\hline \multirow[b]{2}{*}{ Age } & \multicolumn{7}{|c|}{ Systolic } & \multicolumn{7}{|c|}{ Diastolic } \\
\hline & $\begin{array}{c}\text { No } \\
\text { treatment }\end{array}$ & $\leqslant 140$ & -150 & -160 & -170 & -180 & $>180$ & $\begin{array}{c}\text { No } \\
\text { treatment }\end{array}$ & $\leqslant 90$ & -95 & -100 & -105 & -110 & $>110$ \\
\hline \multicolumn{15}{|c|}{ Respondents who treated men and women similarly $(n=241)$} \\
\hline $30-49$ & $12 \cdot 9$ & $1 \cdot 2$ & $17 \cdot 0$ & $33 \cdot 6$ & $26 \cdot 6$ & $5 \cdot 8$ & $2 \cdot 9$ & 0 & $3 \cdot 3$ & $36 \cdot 5$ & $31 \cdot 5$ & $24 \cdot 1$ & $4 \cdot 2$ & 0.4 \\
\hline-69 & $14 \cdot 5$ & 0 & $4 \cdot 2$ & $15 \cdot 8$ & $36 \cdot 1$ & $19 \cdot 1$ & $10 \cdot 4$ & 0 & 1.7 & $9 \cdot 1$ & $29 \cdot 9$ & 36.9 & $17 \cdot 4$ & $5 \cdot 0$ \\
\hline$\geqslant 70$ & $25 \cdot 3$ & 0 & $0 \cdot 4$ & $3 \cdot 3$ & $8 \cdot 3$ & $20 \cdot 3$ & $42 \cdot 3$ & $5 \cdot 8$ & 0 & 0.8 & $10 \cdot 0$ & $20 \cdot 3$ & $21 \cdot 2$ & 41.9 \\
\hline \multicolumn{15}{|c|}{ Respondents who treated men and women differently $(n=89)$} \\
\hline Men & & & & & & & & & & & & & & \\
\hline $30-49$ & $5 \cdot 6$ & $1 \cdot 1$ & $13 \cdot 5$ & 50.6 & $25 \cdot 8$ & $3 \cdot 4$ & 0 & 0 & $1 \cdot 1$ & 31.5 & $56 \cdot 2$ & $10 \cdot 1$ & $1 \cdot 1$ & 0 \\
\hline-69 & $6 \cdot 7$ & 0 & $2 \cdot 3$ & $14 \cdot 6$ & $38 \cdot 2$ & $32 \cdot 6$ & $5 \cdot 6$ & 0 & 0 & $9 \cdot 0$ & $31 \cdot 5$ & $43 \cdot 8$ & $14 \cdot 6$ & $1 \cdot 1$ \\
\hline$\geqslant 70$ & $19 \cdot 1$ & 0 & 0 & $5 \cdot 6$ & $10 \cdot 1$ & $23 \cdot 6$ & $41 \cdot 6$ & $7 \cdot 9$ & 0 & 0 & $4 \cdot 5$ & $24 \cdot 7$ & $20 \cdot 2$ & $42 \cdot 7$ \\
\hline \multicolumn{15}{|l|}{ Women } \\
\hline $30-49$ & $10 \cdot 1$ & $1 \cdot 1$ & $12 \cdot 4$ & $27 \cdot 0$ & $37 \cdot 1$ & $10 \cdot 1$ & $2 \cdot 2$ & 0 & $5 \cdot 6$ & $9 \cdot 0$ & $43 \cdot 8$ & $31 \cdot 5$ & $7 \cdot 9$ & $2 \cdot 2$ \\
\hline-69 & 13.5 & 0 & $1 \cdot 1$ & 2.5 & $19 \cdot 1$ & 49.4 & $14 \cdot 6$ & $1 \cdot 1$ & 0 & $4 \cdot 5$ & $9 \cdot 0$ & $29 \cdot 2$ & $42 \cdot 7$ & 13.5 \\
\hline$\geqslant 70$ & $28 \cdot 1$ & 0 & 0 & $1 \cdot 1$ & $4 \cdot 5$ & $14 \cdot 6$ & $51 \cdot 7$ & $14 \cdot 6$ & 0 & 0 & $1 \cdot 1$ & $10 \cdot 1$ & $24 \cdot 7$ & 49.4 \\
\hline
\end{tabular}

association with the following conditions?" They were then given the option of yes or no for idiopathic atrial fibrillation, thyrotoxicosis, mitral stenosis (before and after mitral valvotomy), rheumatic mitral regurgitation, and the "floppy mitral valve" syndrome.

Transient ischaemic attacks - They were asked to assume that a 55 year old man had presented after three left hemipareses lasting from a few minutes to a few hours and followed by a complete recovery. On examination bruits (not attributed to aortic stenosis) were heard over both carotid arteries. They were then asked if they would take no action; anticoagulate; prescribe a regimen which included aspirin, dipyridamole, or sulphinpyrazone; perform carotid arteriography; consider surgical treatment; or consider surgery only if medical treatment had failed.

Coronary arteriography - Lastly, they were asked to state, "Which, if any, of the following do you regard as indications for coronary arteriography in anticipation that coronary artery bypass surgery may be required?" The following situations were then listed: severe angina unresponsive to medical treatment; a grossly abnormal result from an exercise test; angina attributed to coronary artery spasm (Prinzmetal's variant); survival from successful resuscitation for ventricular fibrillation; recurrent ventricular arrhythmias; or men under 45 who had had myocardial infarction.

Space was left for other approaches to these problems to be listed or for comments to be appended.

\section{Results}

Sixty two physicians returned uncompleted questionnaires because they had retired; of the remaining 579, 341 were completed and returned, giving a response rate of $60 \%$. Of the respondents, $189(55 \cdot 4 \%)$ regarded themselves as general physicians, $102(29 \cdot 9 \%)$ as cardiologists, and $50(14 \cdot 7 \%)$ as physicians with an interest in cardiology.
Those physicians who used different criteria for men and women required higher levels of systolic pressure in the women before taking action (table II). Modal pressures for starting treatment were 151-160 in the youngest men but 161-170 in the women; 161-170 for the middle group of men but 171-180 for the women; but in the oldest age group the modal level for action of $>180$ was the same in both sexes. The diastolic pattern was different in that for the youngest age group the modal level was $96-100$ in both sexes, as was the level of $>110$ for the over 70s. Where these physicians did use different criteria was in the 50-69 year olds, where levels of 101-105 were thought to need action in men but levels of 106-110 were required of the women.

\section{Use of anticoagulants in atrial fibrillation}

Table III shows that atrial fibrillation in association with mitral stenosis was considered to be a high priority for anticoagulation, but mitral regurgitation was a less clear cut priority. Only a few physicians would have considered anticoagulating the other patient groups.

\section{Management of transient ischaemic attacks}

For transient ischaemic attacks the use of platelet modifying agents was considered most valuable, with the possibility of invasive procedures not far behind and anticoagulation accorded a low rating.

\section{Referral for coronary angiography}

Table III shows that patients with intractable angina would, in nearly all cases, have been referred for coronary arteriography whereas all the other options produced much more variable answers among the physicians. 
TABLE III-Physicians' opinions on management of atrial fibrillation and transient ischaemic attacks and referral for coronary arteriography

\begin{tabular}{|c|c|c|c|c|c|}
\hline $\begin{array}{l}\text { Influence of other conditions } \\
\text { on management of atrial fibrillation }\end{array}$ & $\begin{array}{l}\text { No }(\%) \text { who } \\
\text { would give } \\
\text { anticoagulants }\end{array}$ & $\begin{array}{l}\text { Management of transient } \\
\text { ischaemic attacks }\end{array}$ & $\begin{array}{l}\text { No }(\%) \text { who } \\
\text { would recommend } \\
\text { stated action }\end{array}$ & $\begin{array}{l}\text { Referral for coronary } \\
\text { arteriography }\end{array}$ & $\begin{array}{l}\text { No }(\%) \text { who } \\
\text { would recommend } \\
\text { referral for each } \\
\text { type of patient }\end{array}$ \\
\hline $\begin{array}{l}\text { Mitral stenosis before surgery } \\
\text { Mitral stenosis after surgery } \\
\text { Mitral regurgitation } \\
\text { Mitral prolapse } \\
\text { Idiopathic } \\
\text { Thyrotoxic }\end{array}$ & $\begin{array}{r}304(90 \cdot 0) \\
268(79 \cdot 3) \\
177(52 \cdot 3) \\
91(26 \cdot 9) \\
63(18 \cdot 6) \\
52(15 \cdot 4)\end{array}$ & $\begin{array}{l}\text { Give regimen including aspirin, } \\
\text { dipyridamole, or sulphinpyrazone } \\
\text { Consider surgery } \\
\text { Perform carotid angiography } \\
\text { Consider surgery if medical } \\
\text { treatment had failed } \\
\text { Anticoagulate } \\
\text { Take no action }\end{array}$ & $\begin{array}{l}287(85 \cdot 1) \\
284(84 \cdot 2) \\
282(83 \cdot 7) \\
245(72 \cdot 4) \\
131(38 \cdot 8) \\
7(2 \cdot 1)\end{array}$ & $\begin{array}{l}\text { Severe angina unresponsive to } \\
\text { medical treatment } \\
\text { Severely abnormal exercise test result } \\
\text { Variant angina attributed to spasm } \\
\text { Men under } 45 \text { who had had } \\
\text { myocardial infarction } \\
\text { Recurrent ventricular arrhythmias } \\
\text { Survivors of resuscitation from } \\
\text { ventricular fibrillation }\end{array}$ & $\begin{array}{r}322(96 \cdot 4) \\
176(52 \cdot 6) \\
134(40 \cdot 1) \\
\\
128(38 \cdot 3) \\
98(29 \cdot 2) \\
82(24 \cdot 6)\end{array}$ \\
\hline
\end{tabular}

\section{Discussion}

How can we give our patients clear guidance if we fail to recognise major uncertainties in medicine itself? Nowhere is this better exemplified than in the divergent views of our respondents on determining diastolic blood pressure, where decisions that may result in life long medication are being based on end points that differ among practitioners and from the major trials on which our treatment strategies should be based.

"Diastolic anarchy" has prevailed ever since auscultatory end points were first used. Initially, the divergence seemed to be a transatlantic one with White favouring phase $\mathrm{V}^{1}$ and Lewis ${ }^{2}$ and Pickering ${ }^{3}$ opting for phase IV. As Short has reiterated, the "diastolic dilemma" became even more confusing when the first longitudinal risk factor study was mounted in Framingham and used a phase IV end point. ${ }^{4}$ By 1967 the American Heart Association had joined this attempt to reverse transatlantic attitudes and was recommending phase IV, although simultaneously a major treatment trial in the United Kingdom was being planned based on phase $\mathrm{V}$.

Initially, we considered that the differences we had observed between general physicians and cardiologists could reflect this earlier American-United Kingdom divergence, in that cardiologists could have been influenced by the dominance of American based journals in cardiovascular medicine. Other studies within Britain, however, have shown that "diastolic anarchy" does not have such clear cut origins. Hodes et al found a puzzling age relation in general practice in that $60 \%$ of those who qualified before 1934 used phase $\mathrm{V}$, whereas this had fallen to some $30 \%$ in those who qualified after 1964. ' Among hospital staff, however, there was no clear cut age pattern, and the most striking divergence was between what all grades of staff, including nurses, were taught or were teaching $64 \%$ phase IV) and what they actually practised (54\% phase IV and $43 \%$ phase V) ${ }^{6}$

Until we can either agree on a single end point or always record both phase IV and phase V, we face chaos not only in terms of monitoring diastolic blood pressure but also in terms of treatment. If phase IV and phase $\mathrm{V}$ differ by $5 \mathrm{~mm} \mathrm{Hg}$ then at diastolic levels of $70 \mathrm{~mm} \mathrm{Hg}$ or $130 \mathrm{~mm} \mathrm{Hg}$ treatment decisions are unaffected. If, however, two physicians agree to treat patients with diastolic pressures of $100 \mathrm{~mm} \mathrm{Hg}$ and over, then the one who uses phase $\mathrm{V}$ will give a lifetime of treatment to $15 \%$ of his patients while the physician who uses phase IV will treat $25 \%$ of his patients. ${ }^{+} \mathrm{A}$ difference of $10 \%$ in workload, drug costs, and patient inconvenience cannot be ignored so our study confirms that as diastolic anarchy is still with us therapeutic anarchy must also prevail.

Our other questions took our respondents away from facts to opinions. At the time of the circulation of the questionnaire treatment decisions in hypertension ${ }^{8}$ could be based only on the Veterans Administration trials (which dealt only with men), the Hypertension Detection and Follow up Programme (which was not a trial of treatment versus no treatment but of different types of health care delivery), and the Australian National Blood Pressure Study. None of these trials offered guidance on systolic hypertension, ${ }^{8}$ on a United Kingdom population, or on the elderly, as the trials of the Medical Research Council and the European Working Party on Hypertension in the Elderly were still running. ${ }^{9}{ }^{10}$ The attitudes offered by our respondents showed that, despite the lack of current evidence, most of them dealt with men and women similarly, that they used higher pressure thresholds with increasing age, and that many were unconcerned by systolic hypertension, especially in the elderly. This was balanced by overconcern, in the light of the evidence available at the time, for diastolic pressures below the levels at which the benefit of treatment had been established, as $126(37 \%)$ would have started treatment for both men and women at diastolic levels of $91-95 \mathrm{~mm} \mathrm{Hg}$.

By the age of $75,5 \%$ of a population sample have developed atrial fibrillation, ${ }^{11}$ and this increases the risk of stroke 5 to 17 -fold, depending on the conditions associated with it. ${ }^{12}$ About $25-40 \%$ of patients with completed strokes present with atrial fibrillation, yet many of these patients do not have the underlying valvular diseases that were thought by our respondents to require anticoagulation. "Lone" fibrillation and thyrotoxic fibrillation carry a significant risk of systemic embolisation, ${ }^{13}$ yet there is no confirmed evidence on which to base a decision on the use of anticoagulants in any of these groups. ${ }^{13}$ Our respondents' answers show that it would be both ethical and acceptable to mount a trial to compare stroke rates in patients with atrial fibrillation but no valvular disease receiving anticoagulation and in those not receiving anticoagulation.

In transient ischaemic attacks physicians often soothe their own fears about the possibility of a completed stroke by treating a patient, and our respondents' answers are correspondingly at variance with the evidence. Marginal evidence of benefit for men did emerge from the Canadian aspirin-sulphinpyrazone study, ${ }^{14}$ but the uncertainty was sufficient to justify the mounting of a major United Kingdom trial to obtain a more definitive answer. The importance of carotid surgery and therefore of carotid angiography is as yet unestablished, and no adequate studies of anticoagulants in transient ischaemic attacks have ever been mounted ${ }^{13}$; this did not deter our respondents, however, for only $2 \%$ said that they would not use one or other of the list of unproved approaches that we offered them.

The response pattern in respect of coronary angiography did, however, follow the available evidence very closely, perhaps reflecting improvements in trial design, as many of the coronary surgery trials have been large enough to provide definitive answers that physicians can assimilate, unlike the earlier studies on transient ischaemic attacks and fibrillation, which were inadequate in design or in recruitment of patients. The accepted United Kingdom indication for angiographic investigation is severe angina unresponsive to medical treatment, ${ }^{15}$ and this was reflected in the highest positive answer to any of our questions $(96 \cdot 4 \%)$. Doubts about exercise tests as opposed to symptoms, about spasm as a cause of angina, and about patients who had survived myocardial infarction, ventricular arrhythmias, and cardiac arrest were reflected in much lower "action scores," and these uncertainties accord well with the lack of evidence for each of these topics.

Our study thus confirms earlier reports that our performance in the commonest non-invasive circulatory measurement (blood pressure recording) is unsatisfactory for it produces readings that cannot be transferred from doctor to doctor or from trial results to practising physicians. Surely we should put our house in order before embarking on community screening and treatment programmes? The other sections based on opinions show that there is 
considerable scope for incorporating the results of those trials that have already been mounted into clinical attitudes and for initiating trials in common conditions with a serious outcome, such as atrial fibrillation and stroke, to resolve at least some of the uncertainties that confronted our respondents.

We thank the members of the Association of Physicians of Great Britain and Ireland and of the British Cardiac Society for allowing us to encroach on their time.

\section{References}

1 White PD. Heart disease. New York: Macmillan, 1935

2 Lewis T. Diseases of the heart. London: Macmillan, 1942

3 Pickering GW. High blood pressure. London: Churchill, 1955.

4 Short D. The diastolic dilemma. Br Med f 1976; ii:685-6.

5 Hodes C, Rogers PA, Everitt MG. High blood pressure: detection and treatment by general practitioners. Br Med f 1975;i:674-7.
6 Taylor L, Foster MC, Beevers DG. Divergent views of hospital staff on detecting and managing hypertension. BrMed f 1979;i:715-6.

Manek S, Rutherford J, Jackson SHD, Turner P. Persistence of divergent views of hospital staff in detecting and managing hypertension. Br Med f 1984;289:1433-4.

8 Mitchell JRA. Hypertension and stroke. In: Harrison MJG, Dyken ML, eds. Cerebral vascular disease. London: Butterworths, 1983.

9 Medical Research Council Working Party on mild to moderate hypertension. Randomised controlled trial of treatment for mild hypertension: design and pilot trial. BrMed f 1977 ;i:143740.

10 Amery A, De Schaeparijver A. (European working party on high blood pressure in the elderly.) Organisation of a double-blind multi-centre trial on antihypertensive treatment in elderly Organisation of a double-blind multi-centre trial on antihype

11 Campbell A, Caird, FI, Jackson TFM. Prevalence of abnormalities of electrocardiogram in old people. Br Heart f 1974;36:1005-11.

12 Wolf PA, Dawber TR, Emerson Thomas H, Kannel WB. Epidemiologic assessment of chronic atrial fibrillation and risk of stroke: the Framingham study. Neurology (NY) 1978;28:973-7.

13 Lowe GDO. Anticoagulants in cardiac thromboembolism, cardiac surgery, peripheral arterial disease and cerebrovascular disease. In: Meade TW, ed. Anticoagulants and myocardial infarction: a reappraisal. Chichester: Wiley, 1984.

14 Canadian Co-operative Study Group. A randomised trial of aspirin and sulfinpyrazone in threatened stroke. N Engl f Med 1978;299:53-9.

15 Hampton JR. Coronary artery bypass grafting for the reduction of mortality: an analysis of the trials. Br Med f 1984;289:1166-70.

(Accepted 22 fuly 1986)

\title{
Assessment of need for coordinated approach in families with victims of head injury
}

\author{
MARTIN G LIVINGSTON
}

\begin{abstract}
Forty two men with severe head injury, and 41 with minor head injury, together with their families, were assessed at home after the injury. Despite significant impairment with respect to physical symptoms, personality difficulties, and occupational status in severely injured patients after one year, there was a very poor uptake of hospital rehabilitation facilities. In addition, patients' relatives showed significant psychosocial impairment throughout this period.

There is a need for a specialist to coordinate rehabilitation services for patients with head injury and their relatives and, in particular, to integrate physical and psychological aspects of management with a multidisciplinary team approach. Although this task will require specialist hospital teams for future development, at present general practitioners have some specialised knowledge that would enable them to coordinate rehabilitation.
\end{abstract}

\section{Introduction}

Rehabilitating patients with head injury is a priority, not only because of the amount of disability in physical, psychological, and social functioning that occurs in a group of patients who would normally be economically active, ${ }^{12}$ but because those studies that have been performed indicate an appreciable burden on the relatives from having to care for such patients. ${ }^{3}$ Patients may suffer from mobility problems, sensory loss, cosmetic and orthopaedic deficits, and cognitive impairment as well as personality change. They are often dependent on relatives for their care. Relatives complain at

\footnotetext{
Department of Psychological Medicine, University of Glasgow, Glasgow G12 OAA

MARTIN G LIVINGSTON, MD, MRCPSYCH, senior lecturer and honorary consultant at Gartnavel Royal and Gartnavel General Hospitals, Glasgow.
}

present of inadequate or poorly understood information. ${ }^{+}$They may have experienced psychiatric and social difficulties themselves after a patient with head injury has returned home. ${ }^{56}$ Relatives' psychosocial distress often takes the form of disorders of mood, especially anxiety, and a difficulty in fulfilling normal social roles, particularly within the family home. ${ }^{6}$

The present system of management of severe head injury after discharge from hospital in the United Kingdom generally consists of follow up at the clinic of the admitting acute specialty, ${ }^{7}$ though there are some specialist rehabilitation centres. ${ }^{8}$ Family doctors may therefore be left with a group of patients experiencing several handicaps and living in families suffering from psychosocial distress. We studied the need for rehabilitation and its uptake in families with patients suffering from head injury living in the west of Scotland, with a view to examining the role of the general practitioner and hospital services in long term management.

\section{Patients and methods}

A full description of the methods is published elsewhere. ${ }^{56}$ The population studied comprised 42 consecutive men admitted to a regional neurological service with severe head injury and 41 men with minor head injury who had been admitted to a general hospital for observation. Patients were said to have severe head injury if they had post-traumatic amnesia of duration greater than 48 hours and a Glasgow coma score of less than eight." Patients were said to have minor head injury if they had been admitted to the short stay ward for less than 48 hours and had sustained no more than soft tissue damage. Both groups of patients, together with a female relative, were seen at home three months after injury, and the families with severely injured patients were followed up at six and twelve months after injury. If the men were married their wife was seen, while for single men the relative interviewed was the mother; in both cases the relative had to be living with the patient in the family home.

Patients were assessed with the Glasgow assessment schedule,$^{10}$ which is designed to provide a comprehensive rating of the patient's needs for rehabilitation. The schedule has six subscales that evaluate subjective complaints, physical signs, activities of daily living, occupational status, cognitive functioning, and behavioural change. High scores indicate more severe deficits. Problems covered by subjective complaints, physical signs, 